\title{
SUPERVISION EXPERIENCES OF POSTGRADUATE RESEARCH STUDENTS AT ONE SOUTH AFRICAN HIGHER EDUCATION INSTITUTION
}

\author{
M. Cekiso
}

Department of Applied Languages

Tshwane University of Technology

Pretoria, South Africa

e-mail: CekisoMP@tut.ac.za

\section{B. Tshotsho*}

e-mail: BTshotsho@ufh.ac.za

\section{R. Masha*}

e-mail: RMasha@ufh.ac.za

\section{T. Saziwa*}

e-mail: tsaziwa@wsu.ac.za

*Department of English Language and Comparative Literature

University of Fort Hare

Alice, South Africa

\section{ABSTRACT}

This article is based on a study that was conducted at a university based in the Eastern Cape, South Africa. The research aimed to explore and describe challenges that are likely to limit the success of postgraduate research students, mostly focusing on the relationship between students and supervisors. The study adopted a case study design with qualitative data. A self-constructed interview guide with open-ended questions was utilised as the main data collection tool from a sample of 34 postgraduate students from one faculty of the university in question. The study findings revealed that communication breakdown, poor feedback, non-availability of some supervisors and lack of ethical consideration were some of the major factors that contributed to negative supervisory experiences of the students who participated in the study. Based on the findings, the study recommended a number of intervention strategies that could be put in place for both students and supervisors to improve the supervision experience. Among these are the adoption of collaborative cohort model, supervisor training and communication guidelines.

Keywords: feedback, mentoring, postgraduate supervision, supervisors, student, throughput 


\section{INTRODUCTION}

Good supervision is central to successful postgraduate research, yet it is a poorly understood teaching-learning process (Mapasela and Wilkinson 2005). Subsequently, a number of studies have focused on the challenges related to potentially limiting success of postgraduate research students. Such studies have revealed that many postgraduate students drop out or fail to complete their studies within the stipulated time (Naim and Dhanapal 2015; Bitzer 2011; Herman 2011; Wadesango and Machingambi 2011; Dell 2010; Albertyn, Kapp and Bitzer 2008; Stack 2008; Abiddin 2007; Lessing and Schulze 2003).

This situation can be ascribed to numerous factors such as inexperienced or overburdened supervisors, inadequate preparation of candidates, poor planning and management, methodological difficulties, personal problems outside research, insufficient financial support for students, poor relationship between student and supervisor, and overall ineffective infrastructural support for postgraduate studies (Bitzer 2011). Mapasela and Wilkinson (2005) and Calma (2007) found that the kind of supervision students receive is the most important of these factors. According to Frisch and Larson (2000), effective supervision of research students is acknowledged as a crucial factor in the student's successful completion of postgraduate study. In addition, Chiappetta-Swanson and Watt $(2011,8)$ points out that the relationship between a graduate student and an academic supervisor is critical to the success of the learning experience, to the sense of satisfaction of both participants, to the development of research skills, and to the shaping of successful career trajectories of both the student and the supervisor. Waghid (2005) defines the relationship between the supervisor and the student as critical friendship, based on mutual trust and he emphasises that the aim of research is to contribute to social justice. In addition, Collins (2015) states that supervisory relations are complex and dynamic, lengthy, and may involve conflict. Thus, the relationship between the student and the supervisor is defined in different ways by various scholars.

In addition to different definitions is the strong debate about the definition that best describes the relationship between the supervisor and student. The literature on postgraduate supervision highlights that the debate on the definition of the relationship between the supervisor and the student is ongoing. For example, Bak (2011) critiques the definitions provided by Hugo (2009), Waghid (2006) and Fataar (2005) on the basis that each of their arguments had inherent risks. However, the literature on the supervision process has shown that good relationships are associated with good progress and student satisfaction (Mainhard et al. 2009; Chireshe 2012).

Although supervisors are supposed to be key players in the supervision process, Mapasela and Wilkinson (2005) found that many of them are not equipped by their institutions to nurture 
this relationship. Mapasela and Wilkinson argue that some supervisors have little training on the process of supervision. Chiappetta-Swanson and Watt $(2011,4)$ describes the prevalent situation as "muddling through". Unfortunately, this situation negatively affects the progress of the postgraduate students. The following response reveals the frustration of the student interviewed by Nkosi and Nkosi $(2011,11)$ in their study on the experiences of $\mathrm{PhD}$ students:

\footnotetext{
"He seems uncomfortable and bored with me. He lacks passion and enthusiasm, and I feel let down by his inability to assist me to stay focused. Today he tells me this, tomorrow that, and I' $m$ so tired and frustrated about him. Let alone bringing back feedback. Sometimes I get it after three months, sometimes I don't. When he happens to give feedback, you will see that he was actually doing the editing ...."
}

There is no doubt that there are postgraduate students who feel frustrated by the relationship with their supervisors. Therefore, data about students' experiences regarding their relationship with their supervisors is likely to provide important information about their expectations. In addition, Albertyn et al. $(2008,750)$ state that research on the experiences of postgraduate students could help to improve provision of postgraduate programmes by ensuring a focus on the students' needs at hand. Bitzer $(2011,429)$ points out that it seems that little research in South Africa currently exists on what contributes to doctoral success (i.e. the successful completion of a quality doctoral study within a minimum period of time), how doctoral candidates and graduates experience their studies and what personal and knowledge transformation can be associated with successful doctoral research. An understanding of postgraduate students in research supervision may highlight some challenges perceived to be contributing to low throughput rates and poor quality products in South African universities (Chireshe 2012). Lessing and Schulze (2003) add that if the institution has such knowledge it may be able to address problem areas and hence improve the output and quality of postgraduate students. Therefore, the study on which this article draws sought to explore the challenges related to potentially limiting the success of postgraduate research students. This was done by focusing on the experiences of postgraduate research students in one institution of higher learning in South Africa. Based on the above mentioned literature on the benefits of conducting studies on postgraduate students' experiences, it was assumed that the findings of this study would add to our understanding of how to help postgraduate students successfully complete their masters and doctoral programmes.

\section{THE CONTEXT OF THE UNIVERSITY}

The institution where the research was conducted is one of the historically "disadvantaged 
black" institutions which was established to serve black communities before 1994 democracy in South Africa. The institution is located in a predominantly rural are and is serving rural student communities. Lecturers and research supervisors are largely black; and so is its student population. The department of postgraduate and research was manned by one permanent staff member who was also a research supervisor. Although the institution has a vision to promote research, it is characterised by lack of adequate financial, poor internet connectivity, and lack of physical resources like lecture halls. Internet is found in sparse sports and connectivity is sporadic and unreliable.

Postgraduate students are required to conduct research: a mini-dissertation or thesis for masters or doctoral degree respectively. A master's student is allowed to select a supervisor for herself/himself after completing the coursework. On the other hand, a prospective doctoral student is required to produce a letter from a potential supervisor consenting to supervise the student before such a student can be registered for a doctoral degree. Finally, the research student and supervisor commit themselves by signing a university prepared commitment form. According to the university policy, a supervisor is supposed to have one qualification higher than that of the postgraduate student. Thus, a master's student is supposed to be supervised by a PhD holder. A lecturer who has graduated master's degree is only allowed to co-supervise a master student. Faculty research seminars to induct postgraduate research students and supervisors are held annually. Since the student-supervisor ratio is huge, lecturers can have as many students to supervise as they want, there is no limit. At the time the study was conducted, some supervisors were supervising about eighteen (18) postgraduate students.

\section{LITERATURE REVIEW}

\section{Postgraduate supervision}

Postgraduate supervision has been a subject of close scrutiny all around the globe demanding transparency, parity and rigour (Sidhu et al. 2013). Different authors have defined the process of supervision in various ways. For example, Pearson and Brew (2002) define supervision in the academic context as a process to facilitate the student becoming an independent professional researcher and scholar in their field, capable of adapting to various research arenas, whether university- or industry-based. On the other hand, Cryer and Mertens (2003) define postgraduate supervision as a process involving complex, academic and interpersonal skills. These skills, according to Cryer and Mertens, include guiding postgraduate students towards sound proposal preparation, methodological choices, documenting and publishing their research, maintaining both supportive and professional relationships, as well as reflecting on the research process. 
The above description of the supervision process creates a picture of the calibre and stature of a professional who is supposed to assume the role of a supervisor. Mapasela and Wilkinson $(2009,2)$ point out that supervising as a scholarly practice might be effectively promoted where academics themselves are closely involved in research, but also when they reflect, write and publish on their supervisory experiences, seek student feedback and allow peers to critique their work. In addition, Calma (2011) argues that supervisors should ensure that they allow their students expertise, time, feedback, support, commitment and allotted working space. In order to meet the challenging demands of the supervision process, many studies have advocated the training of supervisors (Nkosi and Nkosi 2011; Wadesango and Machingambi 2011). Mutula (2009) adds that postgraduate research is a form of apprenticeship taken under the supervision of senior faculty members and those members must have the right expertise to fulfil the role of a supervisor.

Mouton (2001) points out that some of the responsibilities of the supervisor is to guide, advise, ensure scientific quality and provide the required emotional and psychological support. In addition, Abiddin (2007) proposes that good supervisors care for their students by checking their achievements and commenting upon them. In earlier writing, Moses (1992) emphasised that postgraduate research students have to take responsibility for their research by determining what is required as well as carrying it out. In adding to this notion, Abiddin (2007) argues that students should manage their work independently, without being told step by step what to do. Lessing and Schulze (2003) point out that e-research students have to select a suitable topic, apply relevant research techniques and present their findings accurately. How research students or candidates handle and complete these functions depend to a large extent on the guidance provided by the supervisor.

Some studies have focused on supervisors' experiences of their supervision. For example, Lessing and Schulze (2003) revealed that students had unrealistic expectations and that the supervisor's contribution to the successful completion of a postgraduate student's research had a satisfying effect on the researcher. However, few studies have focused on students' experiences of postgraduate supervision (ASSAF Report 2010,12). Yousefi, Bazrafkan and Yamani (2015), for instance, contend that there is a need for empirical inquiry into the views and opinions of postgraduate studies regarding their supervision experiences. This sentiment is echoed by Conboy and Fonseca (2009) who argue that one simple technique of improving academic success is listening to the study experiences of students. They further state that students, as the primary consumers of the education process, are uniquely positioned to understand the nature of their academic problems better, and that their perceptions can be useful in formulating solutions. In a similar vein, Mahmud and Bretag (2015) observes that the voice 
of postgraduate students on research supervision has not received the attention it deserves. Fataar (2005) acknowledges the student's own voice in the supervisory relationship and advocates for its due space. Fataar $(2013,113)$ further alludes to the need for an acute awareness of, and sensitivity to, the ontological dimension of doing research, which involves the student's being and becoming as a researcher, which implies an increased alertness on the part of supervisors to students' conceptual capacities, learning styles and modes of intellectual processing.

The literature on postgraduate supervision has revealed that postgraduate research students sometimes experience challenges that make it difficult to finish their studies within the stipulated time. Bitzer $(2011,430)$, for instance, points out that such challenges might include the mode of study (e.g. full-time or part-time, in close proximity or at a distance), the level of financial support, the availability and quality of infrastructure, the challenge of gaining research independence, student diversity, academic isolation, the quality of supervision, and the effectiveness of institutional research and monitoring systems. As a response to such challenges some South African higher education institutions have implemented interventions to improve completion rates. For example, the results of a study conducted by Nkosi and Nkosi (2011) about the experiences of $\mathrm{PhD}$ students revealed that students who were part of a cohort group who got extra support beyond their supervisors experienced fewer challenges than students who were limited to the support of their supervisors. In a similar study, Samuels and Vithal (2011) argue that alternative models of doctoral research teaching and learning pedagogy could address the challenge of under-productivity of doctoral graduates in the South African higher education system. Their cohort model of doctoral supervision yielded positive results at the University of KwaZulu-Natal (UKZN). According to Samuels and Vithal (2011), the doctoral collaborative model signals the emergent philosophies of democracy, scaffolding, Ubuntu and serendipity as pillars to frame both the qualitative and quantitative generation of doctoral studies. In this model, the students are assigned to a pool of supervisors and vice versa. This situation benefits both students and supervisors, especially the novice supervisors. Samuels and Vithal state that this model has improved the throughput rate of PhDs at UKZN. Therefore, our study sought to discover the nature of challenges facing postgraduate research students with regard to the supervision during their research journey.

\section{Student-supervisor relationships}

Throughout the period of $\mathrm{PhD}$ studies one of the key figures in a student's life is his/her research supervisor. An effective working relationship between the supervisor and the student thus appears to be crucial (Shariff, Ramli and Ahmad 2014). Peterson (2007), for one, is of the view 
that the student-supervisor relationship is a major determinant of the quality of postgraduate supervision. Similarly, Abiddin (2007) argues that, in the process of supervision, the research student and the supervisor alike need clearly demarcated responsibilities. Abiddin further states that during the period of supervision both should fulfil their roles effectively and maintain a good relationship which often depends upon the characteristics of the persons involved, disciplinary differences in the ways knowledge is advanced, and the different learning tasks students face. In addition, Naim and Dhanapal (2015) argue that the nature of the studentsupervisor relationship is exceedingly crucial as it could determine whether the project/dissertation is successful or a failure. However, Morris (2011) found that the power dynamics in the student-supervisor relationship is perceived to be unequal. The results of the studies conducted on the power differential between a student and a supervisor showed that exploitative, aggressive and intrusive supervision result in study problems (Goodyear, Crego and Johnson, cited 1992 in Morris 2011).

The results of a study conducted by Golde and Dore (2001, cited in Chireshe 2012) on the experiences of postgraduate students revealed that more than 40 per cent of postgraduate students indicated they would pick a different topic if they could start all over again, while 46 per cent stated that they would select a different supervisor if they were given opportunity to do so. According to Chireshe (2012), the selection of the "right" topic and the "right" supervisor is crucial because postgraduate study is supposed to optimise a candidate's future career and research options. The results of a similar study conducted in South Africa by Chireshe (2012) showed that postgraduate students experienced problems related to the following critical issues: the supervisor is too busy to be effective in his/her role; students complained of receiving too little feedback from the supervisors and others raised the concern that supervisors tend to give feedback which conflicts with previous feedback; tensions and conflicting perspectives within the supervisory role; poor communication and disagreements about the research project; selfishness and disrespectfulness; and limited knowledge and expertise in the field of study. In Chireshe's study the respondents attributed the supervisors' busy schedules to the fact that they had many other students to supervise, had heavy lecturing obligations and were required to attend numerous meetings. Also, poor or delayed feedback was identified as problematic by Wadesango and Machingambi (2011) in their study on postgraduate research experiences. They found that at least 75 per cent of student respondents were not satisfied at all with their supervisors' feedback in relation to their research work. Poor feedback by supervisors is a cause for concern, especially in view of Naim and Dhanapal's (2015) assertion that students demonstrate higher levels of intrinsic motivation when they are provided with constructive and informative feedback. Some supervisors thus s seem to deprive their students of the opportunity 
to learn from their mistakes. In addition, Ali and Watson (2016) suggest that timely and constructive feedback could also assist research students to manage their time effectively.

In a study conducted by Yousefi, Bazrafkan and Yamani (2017) on the experiences of research students it was discovered that the workload of the supervisors was a challenge for both supervisors and supervisees. Specifically, due to the lack of time, postgraduate supervisors did not have sufficient time to guide and counsel students and to carry out their duties effectively. In the same study, poor staff development for supervision was observed as a challenge affecting the postgraduate students' progress. As a result, the participants in the study repeatedly confirmed that there was a need to design supervisor development programmes. Furthermore, poor communication between supervisor and supervisee has been identified as negatively affecting the progress of postgraduate studies (Wadesango and Machingambi 2011; Chireshe 2012; Yousefi, Bazrafkan and Yamani 2017). This situation is worrying as Haksever and Manisali (2000) point out that good communication between supervisors and their students is the most important element of supervision. They argue that without open and honest communication it is extremely difficult to identify the nature of challenges experienced by either student or supervisor. Thus, both parties should be open to criticism, willing to listen and to communicate openly (Haksever and Manisali 2000).

In view of the challenges related to postgraduate supervision as they have emerged from relevant literature, the reported study was guided by the following question: What are the challenges identified by PhD and Masters'students with regard to the supervision process?

\section{METHODOLOGY}

\section{Research design}

This section provides a brief discussion of the methodology that was followed to carry out the study. The study adopted a qualitative research approach. Shank $(2002,5)$ defines qualitative approach as "a form of systematic empirical inquiry into meaning" A qualitative approach was seen as the most suitable way of addressing the research question in this case since the study was aimed at gaining an understanding of postgraduate students' experiences with the supervision process. An interview guide with open-ended questions was used to explore the supervision experiences of students at one South African higher education institution.

\section{Participants}

Participants were selected from a population of 48 postgraduate students who were registered in 2016. A total of 34 postgraduate students were selected purposively from the targeted 
institution. Since these students are off campus, we could only access them when they come for consultations with their supervisors or during seminars. The sample consisted of $11 \mathrm{PhD}$ and 23 Master's students who were accessible to the researchers. This sample of students had interacted with their supervisors several times and as such were deemed to have experiences of being supervised.

In this institution, the postgraduate students are mostly full-time employed teachers in rural schools. Therefore, they are all part-time students in the university and usually visit the university in the afternoons. By the time they arrive in the institution, they are visibly exhausted from their work. The range spanned those students who were close to finishing their studies to those who were in their first year of study. The home languages of the students were isiXhosa (62.52\%), Shona (16.67\%), Nyanja (8.33\%), Tshivenda (4.17\%), Bemba (4.17\%) and English $(4.17 \%)$. Ethnically, all participants were Black, due to the institution's predominantly black student population, and 20 were female and 14 were male.

\section{Instrument}

A self-constructed interview guide with open-ended questions by the researchers was utilised as the survey tool for the study. The instrument was distributed by email to all students and contained items requiring students to describe their supervision experiences with their supervisors. The interview guide also sought responses regarding the students' experiences of the institution's administrative system and its learning environment. The elicited responses regarding the supervisory support and guidance received by the students focused on the nature of the interpersonal communication between students and the supervisors and the feedback given by supervisors to students.

\section{Data analysis}

The content of the interview guide was analysed by means of content analysis. According to Maree $(2007,101)$, "content analysis is an inductive and iterative process where we look for similarities and differences in text that would corroborate or disconfirm theory". In the current study the respondents' responses from the interview guide were analysed by making use of a coding process. The aim of coding was to look for themes and patterns that reappear in a single interview. The coding process enabled the researchers to analyse and interpret the data.

\section{FINDINGS}

The following section presents the results according to the themes focussed on in the study, namely, administrative matters and learning environment, support and guidance, poor and 
delayed feedback, supervisors' availability, and lack of ethical considerations.

\section{Administration matters and learning environment}

In terms of administrative matters and learning environment, the students indicated that insufficient information was provided about the course and postgraduate supervision processes and that they mostly obtained vital study information from other students. The following excerpts reveal the situation:

"If you look at the information brochures and compare it with those of other universities, you will laugh. They are badly written, just 2 pages, and do not contain any useful information." [P7]

"We did not have any orientation to tell us about all these processes. Most of us are not resident students and do not even stay in the same town where the university is located so it is important that we get all vital information in advance and not hear it here and there." [P17]

"The university promised to open a computer lab for postgraduate students where they can have access to the internet and computers to work on their research activities. That promise was made two years ago but up to now we do not have that postgraduate lab. We share the few available computer labs with the undergraduate students. This situation affects the progress regarding our theses and dissertations." [P7]

"Our information brochure is very poor. We would like to get information pertaining the registration of postgraduate students, funding opportunities for international and local students and guidelines regarding the different policies and processes involved in masters and doctoral studies." [P28]

Based on the above students' verbal quotations, it is clear that students were not satisfied by the fact that they not treated with the respect they deserved as postgraduate students. They feel that at least a line should be drawn between them and undergraduate students. The fact that they have to share resources with the undergraduate students does not sit well with them. They feel that they deserve better treatment and access to information as postgraduate students.

\section{Support and guidance (poor communication)}

The information deduced from the open ended questions presents a bleak picture of the communication process between the supervisors and students. The following extracts demonstrate poor communication between students and their supervisors:

\footnotetext{
"Since most of us stay and work out of town, it is difficult to contact our supervisors, especially because some of us live in rural areas where there is sometimes no network. You can imagine then when you try to email; they do not get back to you and do not return your calls. And you can't travel all the way to Mthatha when you have not made an appointment because you might not find the supervisor there." [P14]
}

"Our supervisors are very unsupportive, they know we are not resident students but are very poor 
communicators even when we make the effort to contact them. They only contact you when they realize deadlines are near, and then you start panicking because you don't even know what you are supposed to do." [P17]

"We are never told about any of the processes like seminars, Ethics applications etc. and then maybe 1 week before, you are told to quickly put something together for a seminar." [P14]

"Most postgraduate students will tell you, supervisors are very unavailable whether by email or phone and you have to run after them the whole time. This is very discouraging." [P2]

"Even for resident postgrad students, the supervisors are not easily available." [P1]

It appears that communication is poor between supervisors and postgraduate students. This problem is facilitated by the fact that many students do not reside on the university premises but in the nearby rural areas. It appears that the university has not come up with a strategy to facilitate communication between supervisors and their students who reside in the rural areas where there might be no internet facility. To make the situation worse, supervisors do not avail themselves when the postgraduate students take trouble to visit the supervisors. This is another manifestation of poor communication because it seems as if such visits are done without prior appointments.

\section{Poor and delayed feedback}

Based on the information gleaned from the open-ended responses, the majority of the students indicated that the lengthy time taken by the supervisors caused many of them to become disillusioned and disoriented. The students explained that the feedback arrived at a time when they had even forgotten what the discussion issue was, and it became difficult for them to be motivated enough to act on the supervisors' feedback.

The following extracts from the open-ended questions demonstrate students' frustrations with the feedback they received from their supervisors:

"I think supervisors must be taught how to give feedback to postgrad students; they do what they used to do when we were undergrad and give just 1 line comments." [P11]

"My supervisor gives the least feedback ever and sometimes just tells me to go and re-do the work and calls it sub-standard but is not specific about how to fix it." [P5]

"It would help if supervisors would give you or refer you to a well written dissertation for you to emulate, especially because they are unable to guide us with their limited feedback; they assume we should know what to do simply because we are postgrad students." [P13]

It is clear that delayed feedback frustrates the postgraduate students and this could compromise the progress they are supposed to make regarding their studies. The frustration of some students manifests itself in the least feedback that their supervisors provide. It is important that 
supervisors should not assume that the students know the academic writing process but take them through the process. It is also clear that students needed a detailed feedback that would assist them improve on their theses/dissertation writing.

\section{Supervisors' availability}

The information elicited from the open-ended questions revealed that some supervisors did not honour their appointments. The following extracts demonstrate the non-availability of supervisors:

"He always sends me to other students for them to assist me but then I pick up some attitudes from them because they get tired of assisting me. I don't blame them because they do not get paid to help me; it's the job of the supervisor to guide me." [P22]

One day our supervisor scheduled a Saturday workshop for us and we travelled all the way from Butterworth to Mthatha. When we got there, he wasn't there but had asked a fellow student to help us. It was a disaster from the beginning because the student wasn't well equipped to assist us. I thought that was very unprofessional of our supervisor and since he is short tempered, we could not confront him. [P31]

It appears that some supervisors did not display professionalism in the supervision activity. This manifests itself in the situations where a supervisor would ask another student to take care of his/her postgraduate students. Failure to honour an appointment is a serious academic offence on the part of the supervisor. It is also important to note that postgraduate students have confidence on their supervisors because they have walked the path. Referring students to another postgraduate student frustrates the postgraduate student who in some cases has travelled many kilometres to meet their supervisor.

\section{Lack of ethical consideration}

The information from the open-ended questions revealed a lack of ethical consideration from some supervisors, as the following excerpts show:

"My supervisor is very unethical; he shouts at me and sometimes even puts the phone down while we are still talking." [P20]

"My supervisor always comments about other students' work to me and says I must help them because they are not "postgrad material'." [P26]

"After many unsuccessful attempts to meet with my supervisor, he finally agreed to meet me. When I tried to call him he said we can meet in town to discuss my progress. I thought we will at least meet in some quiet place but guess what; we met in a noisy place in Madala Street outside his car. Obviously with all the taxis, cars, music and people making noise, we did not cover much 
and after that he did not even make another follow up meeting." [P2]

From the results it is clear that some supervisors do not adhere to ethical issues. In most cases postgraduate students are adults who need to be treated with dignity. Harassing the postgraduate student cannot be a solution and that kind of behaviour might raise the temper on the part of the student. It is important that supervisors show respect and avoid any form of confrontation with a postgraduate student. Giving a student feedback in a noisy street is not likely to assist the student. At least a conducive atmosphere should prevail where there is no destruction like noise. Talking about other students to one student is unethical on the part of the supervisor. Such behaviours could lead to students undermining each other.

\section{DISCUSSION OF FINDINGS}

From the data it became abundantly clear that the participating students' postgraduate supervision experiences were predominantly negative. Several issues were reported by the students as contributing to such negative experiences and these centred on the guidance given by supervisors to students, poor communication between students and supervisors, poor feedback, supervisors' non-availability and lack of ethical consideration.

The finding focusing on the guidance given to students by supervisors concurs with the literature (Lessing and Schulze 2003; Chireshe 2012) where a lack of mentorship in the supervision process had been observed by Lessing and Schulze (2003). They argued that students are most likely to be satisfied by the supervision process if they get emotional and moral encouragement from their supervisors. However, the findings of our study revealed that the supervisors were unsupportive and also poor in communicating with their students. Therefore, this situation could lead to students failing to finish their studies within the stipulated time.

The finding on students requiring improved communication is also supported by literature. For example, Haksever and Manisali (2000) point out that good communication between supervisors and their students is the most important element of supervision. They argue that without open and honest communication it seems difficult to identify the nature of challenges experienced by either student or supervisor. However, the results of our study reveal that some supervisors are unfriendly and do not encourage open conversations with the students and this situation could affect students' studies negatively. The results of a similar study conducted by Chiappetta-Swanson $(2011,8)$ show that the relationship between a graduate student and an academic supervisor is critical to the success of the learning experience. A number of students (about one third of the students) in the current study were of the opinion that the supervisors 
were helpful, committed to their research and had open channels of communication. Nkosi and Nkosi (2011) assert that such students are likely to succeed in their postgraduate studies. The importance of a positive relationship between student and supervisor has been highlighted in many studies (Kilminster and Jolly 2000; Zhao 2001; Waghid 2006; Abdelhafez 2007; Abiddin 2007). All these authors agree that a positive relationship between student and supervisor is usually associated with good results, something that was found to be lacking in our study. In addition, Abiddin $(2007,11)$ argues that good communication between students and their supervisors is the most important element of supervision.

This study also revealed that students experienced a challenge regarding feedback from their supervisors. Some of their responses pointed to poor feedback from the supervisor as one of the most influential factors in their poor relationships with supervisors. The most influential were cited as supervisors not giving feedback timeously, unconstructive feedback, and the supervisor giving different feedback for the same content. The second reason is that the supervisor takes long to provide students with feedback. Such lack of attention, guidance or interest by supervisors in the development of postgraduate students can lead to demotivation. Calma (2011) argues that supervisors should ensure that they give their students expertise, time, feedback, support, commitment, and allotted working space, which seems not to have been the case in this study. The finding of delayed feedback has also been highlighted by Lessing and Schulze (2003) who noted that students complained about delayed feedback. In another similar study, Wadesango and Machingambi (2011) observed that a significant percentage of their respondents were not satisfied at all with their supervisors' feedback in relation to their research work. This finding is also echoed by Chireshe (2012) who observed that some supervisors provided delayed feedback, lost students' work and sometimes returned students' work without comments. This finding is in line with one of the findings of our study where the students complained about the work returned to them with no clear guidance as to how to deal with the corrections or sometimes with only a few words underlined. This situation could lead to a number of students failing to finish their degrees within the stipulated time or resorting to dropout. Despite the fact that supervisors need to lead candidates towards the successful completion of their theses (Calma 2007), some supervisors in our study were accused of not being available. The finding focussing on the lack of ethical consideration by some supervisors concurs with literature cited by Chireshe (2012) where some students claimed to be harassed by their supervisors.

Overall, the findings revealed that postgraduate students yearned for effective mentorship that would motivate them during their study. It is clear that non-existent of that mentorship could lead to students' frustration and dropout. Effective communication between the student 
and supervisor is significant so as to eliminate the number of barriers that might discourage the student.

\section{CONCLUSION}

The relationship between a postgraduate student and his/her academic supervisor is critical to the quality and success of the learning experience. Often, the research student's academic progress is determined by the nature of such a relationship and thus the supervisor's ability to nurture this relationship is important. The aim of this study was to explore the experiences of postgraduate research students of the supervision process. The study results pointed out that both the administrative and contextual elements in supervision were not supportive of the research students' learning. This is a cause for concern, since both sets of factors play an important role in the student's potential to succeed. The findings also presented a bleak picture of the communication process between supervisors and research students. Literature on postgraduate supervision suggests that effective communication is a key element of the supervision process (Yousefi, Bazrafkan and Yamani 2017; Wadesango and Machingambi 2011; Haksever and Manisali 2000). However, the results of this study revealed poor communication experiences from students in the student-supervisor relationship. This was further underscored by indications of poor or delayed feedback, which students found demotivating. In addition, evidence emerged that the relationship between supervisors and students was characterised by frustration on the part of the students and that limited feedback was seen as a lack of proper supervisory guidance. The study findings further showed a lack of ethical consideration by some supervisors. This is a cause for concern as a good relationship between student and supervisor is supposed to be characterised by trust; it is often equalled to the relationship between a doctor and a patient. It thus seems imperative that trustful relationships should characterise student-supervisor relationships. This study has several limitations that warrant attention in future research. First, since this study was carried out only in one institution of higher learning, the researchers are of the view that a study that focuses on the views of a number of students from different institutions on their experiences of postgraduate supervision is necessary. Second, the researchers felt that further research is necessary that will consider the experiences of the postgraduate research supervisors.

\section{IMPLICATIONS}

The study results hold a number of practical implications for institutional managers such as heads of departments and faculties/ schools, for the training/development of novice supervisors and for postgraduate research students. The researchers suggest that the faculty should 
introduce the Collaborative Cohort Model so that postgraduate research students are exposed to a pool of supervisors with different expertise. Based on the study results, this model is likely to ease the frustration the students are facing at the moment. The model is likely to assist the novice supervisors on how to create a conducive environment for learning so as to improve the postgraduate throughput rate. Based on the study results that supervisors refer their students to other postgraduate students for assistance, the implementation of the collaborative cohort model of supervision is likely to allow students to work as groups and in that way students can learn from each other without taking over the role of a supervisor.

In order to improve the experiences of student supervision identified above, there should be an improved one on one communication. Supervisors could use SMS, Whatsapp and email so that students are assured of constant communication and availability of the supervisor instead of using a notice board which students cannot access because they stay far from campus. There should be clear communication guidelines about the administrative issues. For example, it should be made clear whether it is the responsibility of the supervisor or the department (Research coordinator) to communicate administrative matters to postgraduate students. Supervisors should make more time for consultations, provision of clear guidelines and feedback; and mandatory workshops for postgraduate students and supervisors. The training of supervisors is likely to improve the relationship between supervisors and students. Specifically, the training and mentoring of emerging supervisors by experienced supervisors in order to improve the research throughput and research quality is necessary. In addition to the training, the clarification of roles and responsibilities for both the postgraduate student and the supervisor is important so that both parties are held accountable. In order to ensure adherence to ethical considerations, both students and supervisors should sign contracts that spell out the research related ethics issues. Creating a faculty research assistance centre close to the students that is tasked with research support for students is necessary.

\section{REFERENCES}

Abdelhafez, A. M. 2007. Postgraduate research students' knowledge and attitudes towards good supervisory practice at the University of Exeter. UK: Exeter University.

Abiddin, N. Z. 2007. Postgraduate students' perceptions on effective supervision: A case study at one public university in Malaysia. The Journal of International Social Research 1(1): 18-19.

Albertyn, R. M., C. A. Kapp and E. M. Bitzer. 2008. Profiling exiting postgraduate students' performance and experiences. South African Journal of Higher Education 22(4): 749-772.

Ali, P.A. and Watson, R. 2016. Postgraduate research students' and their supervisors' attitudes towards supervision. International Journal of Doctoral Studies, 11, 227-241.

ASSAF 2010 Report. The PhD study: An evidence based study on how to meet the demands for Highlevel skills in an emerging economy. Assaf consensus report, Pretoria. (Accessed 16 May 2016). 
Bak, N. 2011. Professionalizing the supervision relationship: A reply to Waghid, Fataar and Hugo. South African Journal of Higher Education 25(6): 1047-1061.

Bitzer, E. M. 2011. Doctoral success as ongoing quality business: A possible conceptual framework. South African Journal of Higher Education 25(3): 425-443.

Calma, A. 2007. Postgraduate supervision in the Philippines: Setting the research agenda. The Asia Pacific-Education Researcher 16(1): 91-100.

Calma, A. 2011. Postgraduate research training: Some issues. Higher Education Quarterly 65(4): 368385.

Chiappetta-Swamson, C. and Watt, S. 2011. Supervising and mentoring of postgraduate students: It takes an academy to raise a scholar, Mc Master University. http://cll.mcmaster.ca/ resources/pdf/Supervision (Accessed 12 July 2017).

Chireshe, R. 2012. Research supervision: Postgraduate students' experiences in South Africa. Journal of Social Sciences 31(2): 229-234.

Collins, B. 2015. Reflections on doctoral supervision: drawing form the experiences of students with additional learning needs in two universities. Teaching in Higher Education 20(6): 587-600.

Conboy, J. E. and J. M. B. Fonseca. 2009. Student generated recommendations for enhancing success in secondary science and mathematics. Eurasia Journal of Mathematics, Science \& Technology Education 5(1): 3-14.

Cryer, P. and G. Mertens. 2003. The PhD examination: Support and training for supervisors and examiners. Quality Assurance in Higher Education 11(2): 92-99.

Dell, S. 2010. South Africa: Decline in PhD numbers a major problem. mhtml:file://C:lDocuments and Settings \My D... (Accessed 29 October 2012.

Fataar, A. 2005. Negotiating student identity in the doctoral proposal development process: A personal reflective account. Journal of Education 36: 37-58.

Fataar, A. 2013. A pedagogy of supervision: Knowledgeability through relational engagement. Journal of Education 58: 111-134.

Frisch, J. and K. Larson. 2000. Laissez-faire in research education: An inquiry into a Swedish Doctoral Programme. Higher Education Policy 3(2): 132-155.

Golde, C. M. and T. M. Dore. 2001. At cross purposes: What the experiences of today's doctoral students reveal about doctoral education. Report prepared for The Pew Charitable Trusts. Philadelphia, Pa. http://phd-survey.org/report\%20final.pdf (Accessed 2 March 2016).

Goodyear, R. K., C. A. Crego and M. J. Johnson. 1992. Ethical issues in the supervision of student research: A study of critical incidents. Professional Psychology: Research and Practice 23(3): 203-210.

Haksever, A. M. and F. Manisali. 2000. Assessing supervision requirements of PhD students: The case of construction management and engineering in the UK. European Journal of Engineering Education 25(1): 19-32.

Herman, C. 2011. Obstacles to success-doctoral student attrition in South Africa. Perspectives in Education: The changing face of doctoral education in South Africa: Special Issue, 3 (29): 40-52.

Hugo, W. 2009. Spiralling reference: A case study of apprenticeship into an academic community of practice. South African Journal of Higher Education 23(4): 703-721.

Kilminster, S. M. and B. C. Jolly. 2000. Effective supervision in clinical practice settings: A literature review. Medical Education 34: 827-840.

Lessing, A. C. and S. Schulze. 2003. Lecturers' experience of postgraduate supervision in a distance education context. South African Journal of Higher Education 17(2): 159-168.

Mainhard, T., R. van der Rijst, J. van Tartwijk and T. Wubbels. 2009. A model for the supervisordoctoral student relationship. Higher Education 58(3): 359-373.

Mahmud, S. and T. Bretag. 2015. Integrity in postgraduate research: The student voice. Sci Eng Ethics 
21: $1657-1672$.

Mapasela, M. L. E. and A. C. Wilkinson. 2005. The pains and gains of supervising postgraduate students from a distance: The case of six students from Lesotho, South African Journal of Higher Education 19: $1238-1254$

Maree, K. 2007. First Steps in Research. Pretoria. Van Schaik Publishers.

Morris, S.E. 2011. Doctoral students' experiences of supervisory bullying. Pertanika Journal of Social Sciences and Humanities 19(2): 547-555.

Moses, I. 1992. Good supervisory practice. The Canadian Journal of Higher Education, 15 (3): 1-29.

Mouton, J. 2001. How to succeed in your master's and doctoral studies. Pretoria: Van Schaik.

Mutula, S. M. 2009. Building trust in supervisor-supervisee relationship: Case study of East and Southern Africa. Paper presented at the Progress in Library and Information Science in Southern Africa (PROLISSA) Conference at the University of South Africa (UNISA), March 4-6, 2009.

Naim, N. M. and S. Dhanapal. 2015. Students' perception of the supervisory process: A case study at a private university in Malaysia. Malaysian Online Journal of Educational Management 3(4): 3149.

Nkosi, E. and Z. Nkosi. 2011. Exploring PhD students' supervision experiences at UKZN. Paper presented at the $5^{\text {th }}$ Annual Teaching and Learning Conference of the University of KwaZuluNatal, South Africa. https://www.ncbi.nih.gov/pubmed/21988435 (Accessed on 15 September 2015).

Pearson, M. and A. Brew. 2002. Research training and supervision development. Studies in Higher Education 27(2): 135-150.

Peterson, E. B. 2007. Negotiating academic: Postgraduate research supervision as category boundary work. Studies in Higher Education 32(4): 475-487.

Samuels, M. and L. Vithal. 2011. Emergent frameworks of research teaching and learning in a cohortbased doctoral programme. Perspectives in Education 29: 76-87.

Shank, G. D. 2002. Qualitative research: A personal skills approach. New Jersey: Merrill Prentice Hall.

Shariff, N., K. I. Ramli and R. Ahmad. 2014. Factors contributing to the timely completion of PhD at the Malaysian IPTA: The case of University Utara Malaysia. Proceedings of International Conference on Postgraduate Research, 131-141.

Sidhu, G. K., S. Kaur, C. Y. Fook and F. W. Yunus. 2013. Postgraduate supervision: Exploring Malaysian students' experiences. Procedia Social and Behavioral Sciences 90: 133-141.

Stack, E. M. 2008. Reflections on the supervision of postgraduate research in accounting departments. Paper Presented at the Southern African Accounting Association Conference held on 25-28 at Emperor's Palace, Johannesburg, South Africa.

Wadesango, N. and S. Machingambi. 2011. Post graduate students' experiences with research supervision. Journal of Social Anthropology 2(1): 31-37.

Waghid, Y. 2005. Education, imagination and forgiveness. Journal of Education 37: 225-241.

Waghid, Y. 2006. Reclaiming freedom and friendship through postgraduate student supervision. Teaching in Higher Education 11(4): 427-439.

Yousefi, A., L. Bazrafkan and N. Yamani. 2015. A qualitative inquiry into the challenges and complexities of research supervision: Viewpoints of postgraduate students. Journal of Advances in Medical Education and Professionalism 3(3): 91-98.

Zhao, F. 2001. Transforming quality in research supervision: A knowledge management approach. Quality in Higher Education 9(2): 137-144. 